UDC 913:912.438

LBC 38.2

\title{
GENERAL PLAN OF VOLGOGRAD: A TERRITORIAL ANALYSIS OF CURRENT TRENDS IN THE ECONOMIC DEVELOPMENT OF THE CITY
}

\author{
Nijabat O. Zarbaliyeva \\ Municipal State Institution «City Information Center», Volgograd, Russian Federation
}

\begin{abstract}
The article analyzes the master plan for the development of Volgograd, which defines the main directions of urban development of the city, developed a comprehensive urban zoning of the territory. According to the socio-economic and territorial prerequisites for the reconstruction of the city, a program of priority townplanning measures has been established. The main goal of the urban development of the city is to preserve and increase the architectural, spatial, historical, cultural and landscape identity of the city, creating for the population and future generations favorable for life, a safe and diverse urban environment. The General plan is made to implement the functions of Volgograd both a center of region and considering the close relationships with the cities and settlements within the zone of its direct influence. It is the basis for the development and implementation of long-term and priority programs for the development of urban infrastructure, conservation and development of natural areas, reconstruction of residential and industrial areas, development of public, business and cultural centers, tourism and recreation facilities, integrated landscaping, urban planning projects. The location in the most attractive Volga strip a severe large industrial enterprises, complicating the environmental situation, is a serious obstacle to the harmonious development of Volgograd. The gradual liberation of the Volga riverbank from production functions and their replacement by public-residential and recreational ones is one of the most urgent modern tasks of Volgograd. For such a long city as Volgograd, the development of transport infrastructure is vital. It is the good connectivity of all areas is considered the basis of urban sustainability and the integrity of the urban organism. In the General plan, the development of transport infrastructure is considered from the position of both external and internal transport. the Master plan is focused on the maximum possible disclosure of the existing potential of the Volgograd transport hub, strengthening its role as one of the largest hubs of Federal importance. There are many measures aimed at the development of external transport links. Much attention is paid to the development of inbound tourism. The main objective of the policy in the field of tourism is to create a modern highly efficient and competitive tourist product on the territory of Volgograd.
\end{abstract}

Key words: general plan, urban development, architectural solutions, transport infrastructure.

УДК 913:912.438

ББК 38.2

\section{ГЕНЕРАЛЬНЫЙ ПЛАН Г. ВОЛГОГРАДА: ТЕРРИТОРИАЛЬНЫЙ АНАЛИЗ СОВРЕМЕННЫХ ТЕНДЕНЦИЙ ЭКОНОМИЧЕСКОГО РАЗВИТИЯ ГОРОДА}

\author{
Ниджабат Омар кызы Зарбалиева \\ Городской информационный центр, г. Волгоград, Российская Федерация
}

Аннотация. В статье анализируется Генеральный план развития Волгограда, в котором определены
основные направления градостроительного развития города, разработано комплексное градостроительное
зонирование территории. Согласно социально-экономическим и территориальным предпосылкам реконст-
рукции города установлена программа первоочередных градостроительных мероприятий. Главной целью 
градостроительного развития города, является сохранение и преумножение архитектурно-пространственного, историко-культурного и ландшафтного своеобразия города, создание для населения и будущих поколений благоприятной для жизнедеятельности, безопасной и разнообразной городской среды. Генплан выполнен с учетом осуществления Волгоградом функций столицы Волгоградской области, а также с учетом близких взаимосвязей с городами и поселениями, входящими в зону его непосредственного влияния. Он является основой для разработки и осуществления перспективных и первоочередных программ развития городской инфраструктуры, сохранения и развития территорий природного комплекса, реконструкции жилых и реорганизации производственных территорий, развития общественных, деловых и культурных центров, объектов туризма и отдыха, комплексного благоустройства, проектов планировки территорий города. Гармоничное развитие Волгограда затрудняется расположением в наиболее привлекательной приволжской полосе целого ряда крупных промышленных предприятий, осложняющих экологическую ситуацию. Постепенное освобождение берега Волги от производственных функций и замещение их общественножилыми и рекреационными - одна из актуальнейших современных задач Волгограда. Для такого протяженного города, как Волгоград вопросы развития транспортной инфраструктуры являются жизненно важными. Именно хорошая связанность всех районов считается основой градостроительной устойчивости и целостности городского организма. В генплане развитие транспортной инфраструктуры рассматривается с позицией как внешнего, так и внутреннего транспорта Генеральных план ориентирован на максимально возможное раскрытие имеющегося потенциала Волгоградского транспортного узла, укрепление его роли в качестве одного из крупнейших узлов федерального значения. Предусмотрено много мероприятий, направленных на развитие внешних транспортных связей. Немало внимания уделено и развитию въездного туризма. Главной задачей политики в области туризма является создание на территории Волгограда современного высокоэффективного и конкурентоспособного туристского продукта.

Ключевые слова: генеральный план, градостроительное развитие, архитектурные решения, транспортная инфраструктура.

В настоящее время на территории Российской Федерации проявляется тенденция по разработке многими крупными городами планов своего градостроительного развития. К числу таких городов можно отнести такие, как Санкт-Петербург, Пермь, Ярославль, Екатеринбург и др. Необходимо отметить, что среди российских городов Волгоград был первым городом, подготовившим план в полном соответствии с новым Градостроительным кодексом РФ, соблюдая все требования и условия разработки, согласования и утверждения генпланов.

Генеральный план - это основной вид градостроительной документации о планировании развития территории города, определяющий градостроительную стратегию и условия формирования среды жизнедеятельности [17]. Основной идеей генплана является то, что город должен быть удобным для комфортной жизни людей как в наши дни, так и в будущем, а основная забота градостроителей человек и его нужды: безопасность, удобство, комфорт, качественное транспортное инженерно-техническое обеспечение города, сфера услуг и др. [20]. При этом город всегда является подсистемой государственной экономики и выполняет специальные функции в сис- теме общего распределения труда в стране. Таким образом, определяя перспективы, необходимо выявлять наиболее эффективные функциональные доминанты города с учетом этих двух векторов развития [5].

В генеральном плане определены основные параметры развития. Основными параметрами генплана г. Волгограда являются следующие показатели: перспективная численность населения, объемы строительства и реконструкции жилищного фонда и объектов обслуживания населения, определены необходимые для всех видов строительства территории, разработаны предложения по развитию транспортного комплекса и инженерной инфраструктуры, озеленения и благоустройства территории. При этом были определены основные этапы достижения целей данного плана: первая очередь строительства - до 2015 г. с выделением этапа - до 2010 г.), расчетный срок генерального плана - до 2025 г. и третий этап - прогноз на 30 лет [11].

Генеральный план был разработан авторским коллективом петербургских проектировщиков научно-проектного института пространственного планирования «ЭНКО» при участии московских и волгоградских специалистов. Руководителем проекта является О.В. Кра- 
совская. Большой вклад в создание плана оказали специалисты департамента архитектуры Волгограда. В целом же генплан развития города на 20 лет разработан на основе анализа реализации предыдущего генерального плана 1984 г., современной ситуации использования территории города, также на основе сравнения тенденций градостроительного развития Волгограда и крупнейших мегаполисов России и мира [11].

Генплан Волгограда был разработан в короткие сроки с конца 2003 г. до начала 2006 г., с учетом коренных изменений, которые произошли во всех областях жизни страны, области и города и, в особенности, с учетом изменившегося градостроительного законодательства. В 2017 г. был опубликован проект о внесении изменений в Генеральный план Волгограда, который был подготовлен муниципальным бюджетным учреждением «Институт градостроительного планирования Волгограда «Мегаполис» по муниципальному заданию на 2016 г. в соответствии с утвержденным градостроительным заданием, выданным комитетом по градостроительству и архитектуре Волгограда в 2015 г., и с учетом дополнительной информации, предоставленной департаментом по градостроительству и архитектуре администрации Волгограда в 2016 году [11].

Следует отметить, что генплан выполнен с учетом осуществления Волгоградом функций столицы Волгоградской области, а также с учетом близких взаимосвязей с городами и поселениями, входящими в зону его непосредственного влияния [1]. Это то, что в проекте закреплено за градостроительной системой «Большой Волгоград». Кроме того, генплан является основой для разработки и осуществления перспективных и первоочередных программ развития городской инфраструктуры, сохранения и развития территорий природного комплекса, реконструкции жилых и реорганизации производственных территорий, развития общественных, деловых и культурных центров, объектов туризма и отдыха, комплексного благоустройства, проектов планировки территорий города $[12 ; 18]$.

Исходя из социально-экономических предпосылок, позитивных и негативных факторов градостроительного развития Волгогра- да, в генплане определены основные направления развития города, разработано зонирование территории, определена программа первоочередных мероприятий. Сам генплан состоит их четырех частей:

- комплексный градостроительный анализ территории;

- стратегические направления градостроительного развития города;

- градостроительные мероприятия по основным функциональным зонам;

- система первоочередных мероприятий.

Большой раздел генплана отведен градостроительному зонированию территории города (см. рис. 1). Функциональное зонирование определяет наиболее целесообразное назначение территории, занятой участками общественных, жилых, производственных и природных объектов. Строительное зонирование устанавливает для каждой планировочной единицы предельные параметры застройки территории, занятых участками малоэтажной, среднеэтажной, многоэтажной застройки, и совокупную площадь застройки.

Важное значение для города имеют зоны транспортной и инженерной инфраструктур 3382 га. Объекты городских насаждений общего пользования занимают 1293 га, что гораздо ниже нормативных требований [15].

Планировочной особенностью города является историческое размещение в береговой зоне р. Волга крупных производственных объектов, на основе которых образовались крупные по площади промышленные районы - Тракторный завод, завод «Баррикады», завод «Красный Октябрь», промзона «Речпорт», Ельшанская промзона, завод им. Ермана, промзона производственного объединения «Химпром», промзона «Судоверфь», Заканальный промузел (см. рис. 1). Предприятия, расположенные в данных промузлах, имеют градообразующее значение, но, одновременно, занимают ценные в градостроительном отношении прибрежные территории и являются приоритетными источниками загрязнения, оказывают негативное воздействие на экологическую ситуацию в общегородском масштабе [3]. Постепенное освобождение берега Волги от производственных функций и замещение их общественно-жилыми и рекреационными - одна из актуальнейших современных задач Волгограда [7; 13]. 
Н.О. Зарбалиева. Генеральный план г. Волгограда

Раздел «Жилищное строительство» разрабатывался с учетом реализации национального проекта. В генеральном плане заложен показатель жилищной обеспеченности к расчетному сроку в 27 м $^{2}$ на человека (при нынешнем по- казателе порядка $20 \mathrm{~m}^{2}$ ). При этом жилищный фонд к концу расчетного срока составит около 30 млн м ${ }^{2}$ общей площади. Предполагается, что среднегодовой объем нового жилищного строительства составит около полумиллиона $\mathrm{m}^{2}$

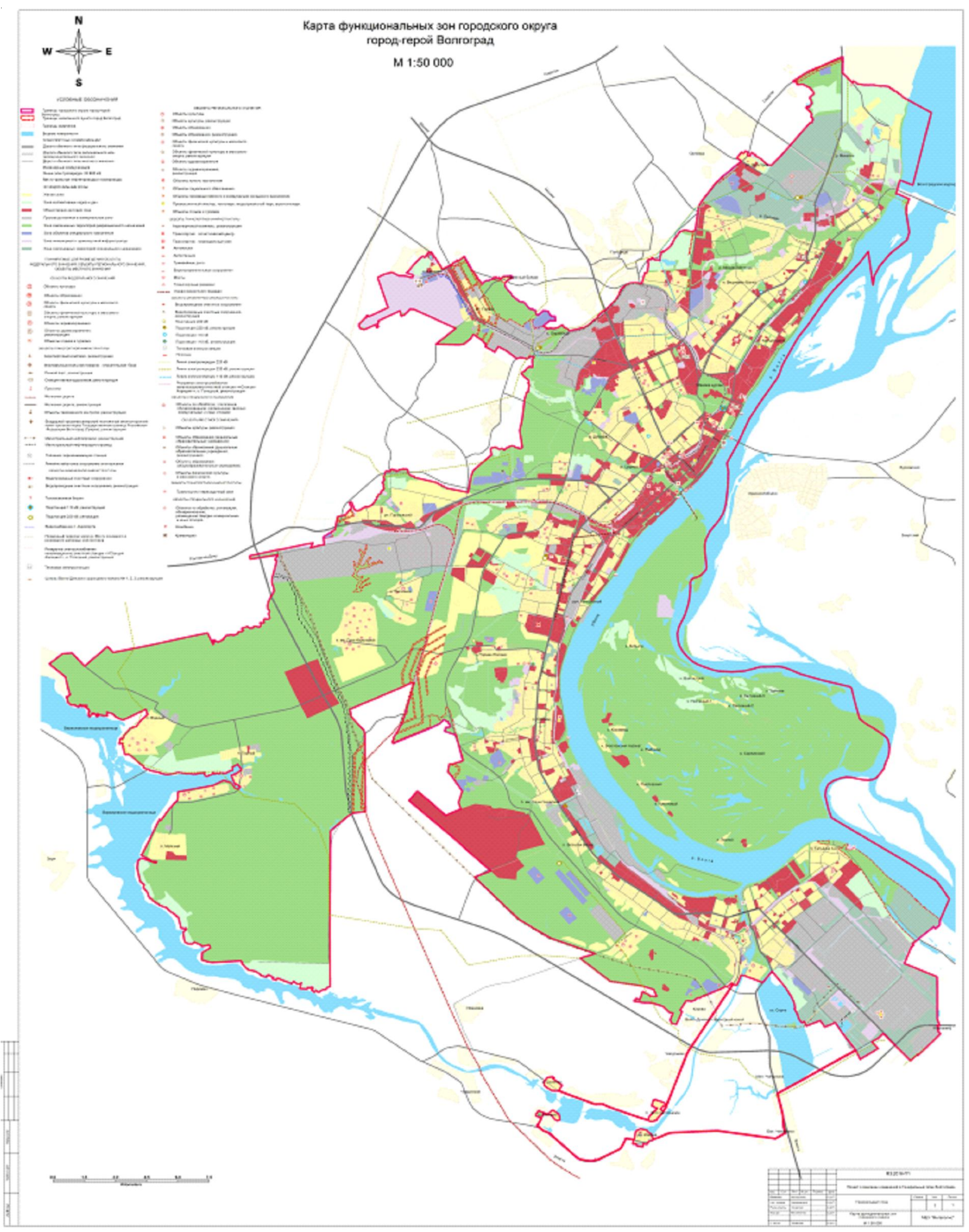

Рис. 1. Карта функциональных зон городского округа города-героя Волгограда 
общей площади. Комплексная застройка и благоустройство районов нового жилищного строительства с полным инженерным оборудованием территории и строительством объектов социальной сферы, устройством спортивных и парковых зон является важным условием осуществления строительной программы [15].

Другим условием является эффективное использование территорий города. Под ним подразумевается выборочное уплотнение территорий существующих микрорайонов и кварталов в соответствии с нормативами плотности; надстройка зданий и устройство мансардных этажей; размещение обслуживающих объектов в комплексе с существующими и новыми жилыми зданиями. Проектировщики включили в принципы жилищного строительства и разнообразие градостроительных решений в реконструкции и новой застройке различных районов Волгограда. При столь крупных объемах жилищного строительства нельзя, чтобы город застраивался по типовым схемам. Выразительные архитектурные решения предполагают развитие традиционных типов городских пространств - квартал, площадь, пешеходная улица, двор, бульвар, сквер [21]. Кстати, исторические районы города, которые горожане называют в числе самых привлекательных, и решены в этом ключе.

Для такого протяженного города, как Волгоград вопросы развития транспортной инфраструктуры являются жизненно важными [2]. Именно хорошая связанность всех районов считается основой градостроительной устойчивости и целостности городского организма [19]. В генплане развитие транспортной инфраструктуры рассматривается с позицией как внешнего, так и внутреннего транспорта [5; 11]. Волгоград стоит в ряду основных опорных транспортных узлов России в системе международных евроазиатских и внутрироссийских транспортных коридоров «Север - Юг» и «Транссиб». Поэтому решение проблем развития транспортной инфраструктуры Волгограда проектировщиками явилось одной из приоритетных задач, определяющих возможность активизации экономических, культурных и туристических связей города и улучшения качества жизни (см. рис. 2).

Генеральных план ориентирован на максимально возможное раскрытие имеющего- ся потенциала Волгоградского транспортного узла, укрепление его роли в качестве одного из крупнейших узлов федерального значения. По развитию внешних транспортных связей предусмотрено много мероприятий. В частности, предложена реконструкция по международным стандартам федеральных автодорог Москва - Астрахань (М-6 «Каспий»), Саратов - Волгоград, Волгоград - КаменскШахтинский. Неотъемлемой частью этих проектов станет строительство сети обходных автодорог вокруг Волгограда.

Детально проработаны разделы, касающиеся развития внутригородской улично-дорожной сети. К их числу отнесем усиление транспортных связей в продольном направлении: продолжение на юг 1-й Продольной магистрали - ул. Рабоче-Крестьянская - ул. Электролесовская, организация западного дублера 2-й Продольной магистрали (ул. Московская, П. Осипенко, Азизбекова, Феодосийская), продолжение строительства в южном направлении набережной р. Волги (Нулевая Продольная магистраль). Предложены мероприятия по созданию трасс общегородского значения в поперечном направлении. В генплане также предполагается разгрузка центра города от легковых автомобилей путем отвода транзитного движения, создания «перехватывающих» автостоянок у въездов в центр и в город.

Разумеется, проект внесения изменений в генплан учитывал участие Волгограда в качестве принимающего города в чемпионате мира по футболу в 2018 году. Были выделены территории для строительства стадионов, гостиничного и общественно-делового комплекса, возможность реконструкции существующих железнодорожного вокзала и автовокзала. Запланирована территория для строительства нового автовокзала на пересечении 2-й Продольной магистрали и мостового перехода через Волгу [4].

Немаловажное значение имеет развитие туристического комплекса [6]. Главной задачей политики в области туризма является создание на территории Волгограда современного высокоэффективного и конкурентоспособного туристского продукта, обеспечивающего широкие возможности для удовлетворения потребностей населения в туристских услугах [15]. 


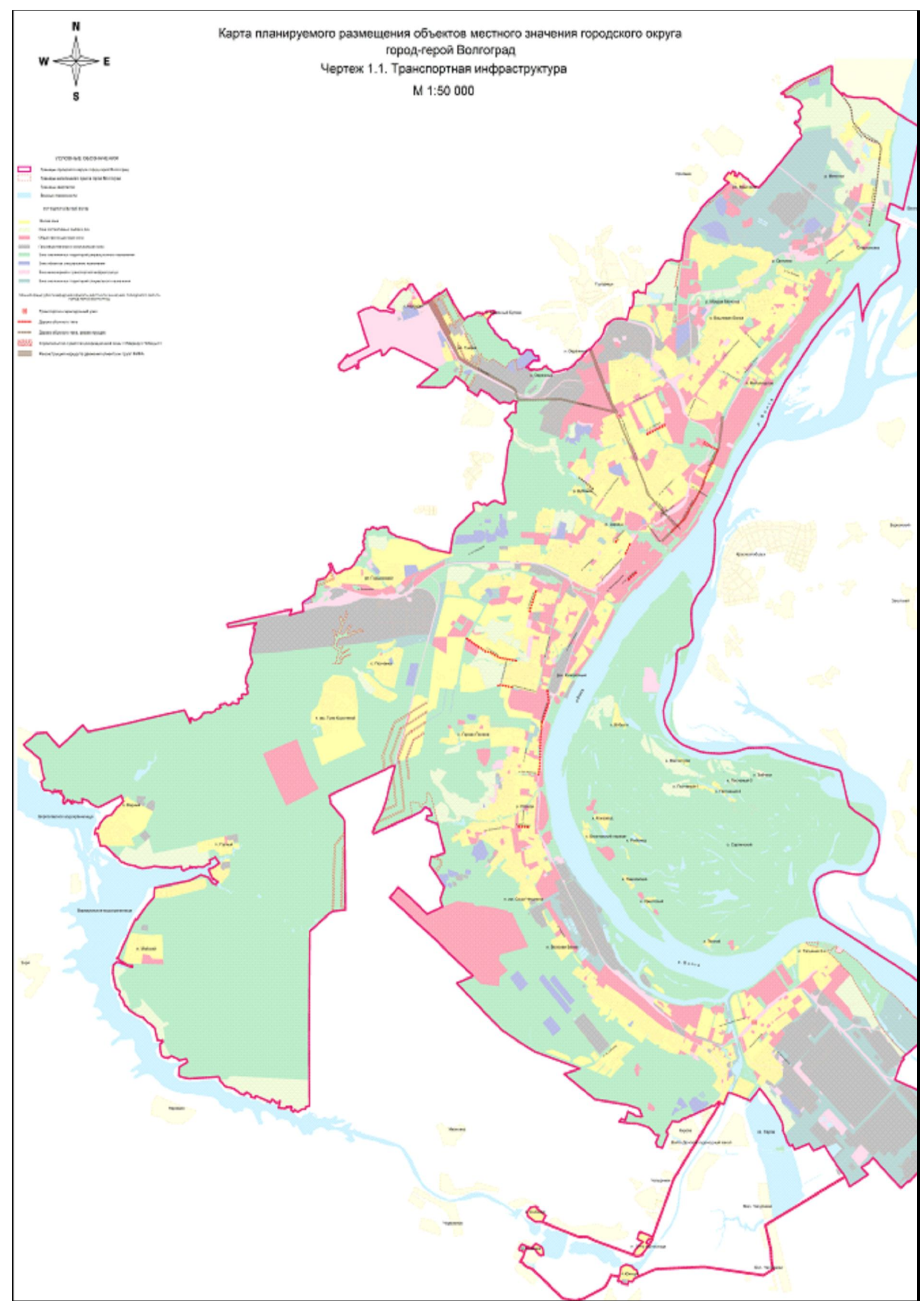

Рис. 2. Карта планируемого размещения объектов местного значения городского округа города-героя Волгограда. Транспортная инфраструктура 


\section{ЭКОЛОГИЯ И ПРИРОДОПОЛЬЗОВАНИЕ}

Основными задачами на период действия настоящего Генерального плана в области туризма является увеличение объема «въездного» (в том числе местного) туризма и смещение акцентов в использовании его туристско-экскурсионного потенциала с военно-исторического на культурно-познавательный [16]. Туристические ресурсы, которыми располагает Волгоград, способны привлечь значительное количество туристов не только России, но и из-за рубежа [10].

Факторами, способствующими развитию туризма в Волгограде являются:

- выгодное географическое положение;

- наличие туристского потенциала на территории города;

- наличие природно-рекреационных ресурсов в городе и области;

- наличие бальнеологических ресурсов в области (сухой климат, минеральные воды, лечебные грязи);

- этно-конфессиональное многообразие региона [9].

Наиболее перспективными для основной массы туристов, по всей вероятности, станут следующие виды туризма:

- познавательный;

- деловой;

- событийный;

- экологический;

- лечебно-оздоровительный [8].

В настоящее время огромный потенциал Волгограда, как объекта познавательного, экологического, событийного (фестивальный, выставочный и т. д.), спортивно-оздоровительного видов туризма явно используется не в полном объеме [14].

Эта важнейшая и прибыльная отрасль экономики города требует расширения и развития. В 2005 г. в Волгограде въездной и местный туризм по объему операций составлял не более $7 \%$, тогда как выездной - $93 \%$. Предположительно, основной причиной того факта, что въездной и местный туризм занимает так мало места в экономике Волгограда, можно считать сложившееся в России (СССР) и за рубежом на протяжении нескольких десятилетий мнение, что Волгоград (Сталинград) интересен только как место величайшего события Второй мировой войны - Сталинградской битвы.
Можно заключить, что все основные изменения, включенные в генплан города-героя Волгограда, направлены на обеспечение существующего прогресса в развитии основных секторов экономики, повышение инвестиционной привлекательности города, повышение уровни жизни и условий проживания населения, достижения долговременной экологической безопасности города и смежных территорий, рациональное использование всех видов ресурсов, современные методы организации транспортных и инженерных систем, а также создание благоприятной для жизни городской среды.

Волгоград имеет все возможности активного экономического развития и совершенствования городской среды, этому способствуют природные, экономико-градостроительные и планировочно-территориальные факторы.

Градостроительное развитие города проходит стабильно.

Целесообразно сопряженное развитие населенных мест, входящих в состав городских агломераций, разработка и реализация единого документа, определяющего порядок градостроительной деятельности.

\section{СПИСОК ЛИТЕРАТУРЫ}

1. Аляев, В. А. Сельское расселение как основа устойчивого развития Волгоградской области / В. А. Аляев, М. В. Аляев // Грани познания. - 2013. № 3 (23). - С. 58-69.

2. Аляев, В. А. Формирование территориальной структуры хозяйства и транспортной инфраструктуры Волгоградской региона (конец XIX конец ХХ вв.) / В. А. Аляев, М. В. Аляев. - Волгоград : Изд-во ВолГУ, 2018. - $203 \mathrm{c.}$

3. Анопин, В. Н. Адаптивно-ландшафтные технологии восстановления и преобразования насаждений Зеленого кольца г. Волгограда / В. Н. Анопин, Д. А. Солодовников, Е. А. Степанова // Вестник Волгоградского государственного архитектурно-строительного университета. Серия: Строительство и архитектура. -2019 . - № 1 (74). - С. 138-150.

4. Анучина, Н. А. Характеристика деятельности коллективных средств размещения Волгоградской области в период 2010-2015 гг. / Н. А. Анучина, О. Ю. Зеленская, Д. А. Семенова // Антропогенная трансформация геопространства: история и современность : Материалы IV Междунар. науч.- 
практ. конф. - Волгоград : Изд-во ВолГУ, 2017. C. 61-66.

5. Барсуков, И. Е. Инновационные механизмы обеспечения устойчивого развития крупного города / И. Е. Барсуков. - Электрон. текстовые дан. Режим доступа: https://lib.rsl.ru/01003313908.

6. Вишняков, Н. В. Мониторинг туристскорекреационной деятельности особо охраняемых природных территорий как эффективный индикатор прогнозируемого развития туристских территорий / Н. В. Вишняков, О. Ю. Зеленская // Юг России: экология, развитие. -2018. - Т. 13, №4 (49). -С. 119-128.

7. Дьяченко, Н. П. Геоэкологическая оценка добычи песчаного материала (на примере песчаных карьеров Волгоградской области) / Н. П. Дьяченко, Н. М. Хаванская // Известия высших учебных заведений. Северо-Кавказский регион. Серия: Естественные науки. - 2011. - № 2 (162). - С. 81-85.

8. Канищев, С. Н. Региональные аспекты рекреационной географии (зональный и азональный подход к анализу рекреационных процессов) / С. Н. Канищев, Д. А. Солодовников // Взаимодействие природных и общественных систем: региональный аспект исследований : коллектив. моногр. / под ред. А. В. Холоденко. - Волгоград : Изд-во ВолГУ, 2013. - С. 218-243.

9. Курсакова, Н.А. Природно-рекреационный потенциал Волгоградского Заволжья как предпосылка развития туристической деятельности / Н. А. Курсакова // Геология, география и глобальная энергия. - 2013. - № 4 (51). - С. 168-175.

10. Курсакова, Н. А. Развитие новых видов активного зимнего отдыха в Нижнем Поволжье / Н. А. Курсакова // Вестник Волгоградского государственного университета. Серия 11. Естественные науки. - 2017. - № 3 (21). - C. 58-64. - DOI: https://doi.org/10.15688/jvolsu11.2017.3.8.

11. Решение Волгоградской городской думы об утверждении генерального плана Волгограда. Электрон. текстовые дан. - Режим доступа: http:// docs.cntd.ru/document/446505691.

12. Фесенко, В. В. Волгоградская агломерация: специфика формирования, современное состояние и пространственные перспективы / В. В. Фесенко, Л. В. Деточенко // Полимасштабные системы «центр-периферия» в контексте глобализации и регионализации: теория и практика общественно-географических исследований : Материалы междунар. науч. конф. (Шестая Ежегодная научная Ассамблея АРГО). - Симферополь, 2015. -С. 118-126.

13. Филиппов, О.В.Пятидесятилетние итоги развития берегов Волгоградского водохранилища / О. В. Филиппов, Д. А. Солодовников // Стрежень: Научный ежегодник. - 2010. - № 8. - С. 135-139.

14. Хаванская, Н. М. Проектирование интерактивной туристической карты Волгоградской об- ласти / Н. М. Хаванская // Геоинформационное картографирование в регионах России : материалы $\mathrm{X}$ Всерос. науч.-практич. конф. - Воронеж : Воронеж. гос. ун-т, 2018. - С. 166-169.

15. Шевцова, Е. Б. Разработка методики обоснования инвестиционно-строительной привлекательности развития городских территорий / Е. Б. Шевцова. - Электрон. текстовые дан. - Режим доступа: https://dlib.rsl.ru/01003314968.

16. Evaluation of landscape-ecological parameters of steppe geosystems for regulation of recreational impact. / S. Kirillov, S. Kanischev, A. Kholodenko, D. Solodovnikov // International Multidisciplinary Scientific GeoConference Surveying Geology and Mining Ecology Management, SGEM 14. -2014. - P. 251-258.

17. Rabin, Ya. Federal urban transportation policy and the highway planning process in metropolitan areas / Ya. Rabin // Annals of the American Academy of Political and Social Science. - 1980. Vol. 451, № 1. - P. 21-35.

18. Rietveld, P. Methods for planning urban facilities in rural areas of developing countries: a comparison of approaches / P. Rietveld // International Regional Science Review. - 1992. - Vol. 15, № 3. P. 345-356.

19 Shesterov, E. Elaboration of a coordinated transport system in course of territorial planning of urban areas development / E. Shesterov, I. Drozdova // Transportation Research Procedia. - 2017. P. 608-612.

20. Supermarket access, transport mode and BMI: the potential for urban design and planning policy across socio-economic areas / M. Murphy, M. J. Koohsari, H. Badland, B. Giles-Corti // Public Health Nutrition. - 2017. - Vol. 20, № 18. P. 3304-3315.

21. Yeomans, M. G. Some dimensions of a planning problem residential-agricultural land use conflict in metropolitan rural-urban fringe areas / M. G. Yeomans. - Vancouver, 2002. - 263 p.

\section{REFERENCES}

1. Alyaev V.A., Alyaev M.V. Selskoe rasselenie kak osnova ustoychivogo razvitiya Volgogradskoy oblasti [Rural Settlement As a Basis for Sustainable Development of the Volgograd Region]. Grani poznaniya [Facets of Knowledge], 2013, no. 3 (23), pp. 58-69.

2. Alyaev V.A., Alyaev M.V. Formirovanie territorialnoy struktury hozyaystva i transportnoy infrastruktury Volgogradskogo regiona (konets $X I X$ - konets $X X v v$.) [Formation of the Territorial Structure of the Economy and Transport Infrastructure 
of the Volgograd Region (Late XIX - Late XX Centuries)]. Volgograd, Izd-vo VolGU, 2018. 203 p.

3. Anopin V.N., Solodovnikov D.A., Stepanova E.A. Adaptivno-landshaftnye tekhnologii vosstanovleniya i preobrazovaniya nasazhdeniy Zelenogo koltsa g. Volgograda [Adaptive Landscape of Technology for the Recovery and Transformation of the Spaces of the Green Ring of the City of Volgograd]. Vestnik Volgogradskogo gosudarstvennogo arkhitekturno-stroitelnogo universiteta. Seriya: Stroitelstvo i arhitektura [Bulletin of Volgograd State University of Architecture and Construction. Series: Construction and Architecture], 2019, no. 1 (74), pp. 138-150.

4. Anuchina N.A., Zelenskaya O.Yu., Semenova D.A. Kharakteristika deyatelnosti kollektivnykh sredstv razmeshcheniya Volgogradskoy oblasti v period 2010-2015 gg. [Characteristics of Collective Accommodation Facilities of the Volgograd Region in the Period 2010-2015]. Antropogennaya transformatsiya geoprostranstva: istoriya $i$ sovremennost: Materialy IV Mezhdunarodnoy nauchno-prakticheskoy konferentsii [Anthropogenic Transformation of Geospatial Space: History and Modernity. Proc. of the IV International Scientific and Practical Conference]. Volgograd, Izd-vo VolGU, 2017, pp. 61-66.

5. Barsukov I.E. Innovatsionnye mehanizmy obespecheniya ustoychivogo razvitiya krupnogo goroda [Innovative Mechanisms for Sustainable Development of a Large City]. URL: https://dlib.rsl.ru/ 01003313908.

6. Vishnyakov N.V., Zelenskaya O.Yu. Monitoring turistsko-rekreatsionnoy deyatelnosti osobo okhranyaemykh prirodnykh territoriy kak effektivnyy indikator prognoziruemogo razvitiya turistskikh territoriy [Monitoring of Tourist and Recreational Activities of Specially Protected Natural Areas As an Effective Indicator of the Projected Development of Tourist Areas]. Yug Rossii: ekologiya, razvitie [South of Russia: Ecology, Development], 2018, vol. 13, no. 4 (49), pp. 119-128.

7. Dyachenko N.P., Khavanskaya N.M. Geoekologicheskaya otsenka dobychi peschanogo materiala (na primere peschanykh karyerov Volgogradskoy oblasti) [Geoecological Assessment of Sand Material Extraction (On the Example of Sand Quarries of the Volgograd Region)]. Izvestiya vysshikh uchebnykh zavedeniy. Severo-Kavkazskiy region. Seriya: Estestvennye nauki [Proceedings of higher educational institutions. North Caucasus region. Series: Natural Sciences], 2011, no. 2 (162), pp. 81-85.

8. Kanishchev S.N., Solodovnikov D.A. Regionalnye aspekty rekreatsionnoy geografii (zonalnyy i azonalnyy podkhod k analizu rekreatsionnykh protsessov) [Regional Aspects of
Recreational Geography (Zonal and Azonal Approach to the Analysis of Recreational Processes)]. Vaimodeystvie prirodnykh i obshchestvennykh sistem: regionalnyy aspekt issledovaniy: kollektivnaya monografiya [Interaction of Natural and Social Systems: Regional Aspect of Research. Collective Monograph]. Volgograd, Izd-vo VolGU, 2013, pp. 218-243.

9. Kursakova N.A. Prirodno-rekreatsionnyy potentsial Volgogradskogo Zavolzhyya kak predposylka razvitiya turisticheskoy deyatelnosti [Natural and Recreational Potential of the Volgograd Volga Region As a Prerequisite for the Development of Tourism]. Geologiya, geografiya $i$ globalnaya energiya [Geology, Geography and Global Energy], 2013, no. 4 (51), pp. 168-175.

10. Kursakova N.A. Razvitie novykh vidov aktivnogo zimnego otdykha $\mathrm{v}$ Nizhnem Povolzhye [Development of New Types of Active Winter Recreation in the Lower Volga Region]. Vestnik Volgogradskogo gosudarstvennogo Universiteta. Seriya 11, Estestvennye Nauki [Science Journal of VolSU. Natural Sciences], 2017, vol. 3 (21), pp. 58-64. DOI: https://doi.org/10.15688/jvolsu11.2017.3.8.

11. Reshenie Volgogradskoy gorodskoy dumy ob utverzhdenii generalnogo plana Volgograda [Decision of the Volgograd City Duma on Approval of the Master Plan of Volgograd]. URL: http:// docs.cntd.ru/document/446505691.

12. Fesenko V.V., Detochenko L.V. Volgogradskaya aglomeratsiya: spetsifika formirovaniya, sovremennoe sostoyanie i prostranstvennye perspektivy [Volgograd Agglomeration: Specifics of Formation, Current State and Spatial Prospects]. Polimasshtabnye sistemy «tsentr - periferiya» $v$ kontekste globalizatsii $i$ regionalizatsii: teoriya i praktika obshchestvennogeograficheskikh issledovaniy : Materialy mezhdunarodnoy nauchnoy konferentsii (VI Ezhegodnaya nauchnaya Assambleya ARGO) [Center-Periphery Multi-Scale Systems in the Context of Globalization and Regionalization: Theory and Practice of Socio-Geographical Research: Proceedings of the International Scientific Sonference (Sixth Annual Scientific Assembly of ARGO)]. Simferopol, 2015, pp. 118-126.

13. Filippov O.V., Solodovnikov D.A. Pyatidesyatiletnie itogi razvitiya beregov Volgogradskogo vodohranilishcha [Fifty-Year Results of the Development of the Banks of the Volgograd Reservoir]. Strezhen: Nauchnyy ezhegodnik [The Fairway: Scientific Yearbook], 2010, no. 8, pp. 135-139.

14. Khavanskaya N.M. Proektirovanie interaktivnoy turisticheskoy karty Volgogradskoy oblasti [Designing an Interactive Tourist Map of the Volgograd Region]. Geoinformatsionnoe kartografirovanie $v$ regionakh Rossii: materialy $X$ Vserossiyskoy nauchno-prakticheskoy konferentsii 
[Geoinformation Mapping in Russian Regions: Proc. X All-Russian Scientific and Practical Conference]. Voronezh, Voronezhskiy gosudarstvennyy universitet, 2018, pp. 166-169.

15. Shevtsova E.B. Razrabotka metodiki obosnovaniya investitsionno-stroitelnoy privlekatelnosti razvitiya gorodskikh territoriy [Development of Methodology for Substantiation of Investment and Construction Attractiveness of Urban Development]. URL: https://dlib.rsl.ru/ 01003314968.

16. Kirillov S., Kanischev S., Kholodenko A., Solodovnikov D. Evaluation of Landscape-Ecological Parameters of Steppe Geosystems for Regulation of Recreational Impact. International Multidisciplinary Scientific GeoConference Surveying Geology and Mining Ecology Management, SGEM 14, 2014, pp. 251-258.

17. Rabin Ya. Federal Urban Transportation Policy and the Highway Planning Process in
Metropolitan Areas. Annals of the American Academy of Political and Social Science, 1980, vol. 451, no. 1, pp. 21-35.

18. Rietveld P. Methods for Planning Urban Facilities in Rural Areas of Developing Countries: A Comparison of Approaches. International Regional Science Review, 1992, vol. 15, no. 3, pp. 345-356.

19. Shesterov E., Drozdova I. Elaboration of a Coordinated Transport System in Course of Territorial Planning of Urban Areas Development. Transportation Research Procedia, 2017, pp. 608-612.

20. Murphy M., Koohsari M.J., Badland H., Giles-Corti B. Supermarket Access, Transport Mode and BMI: the Potential for Urban Design and Planning Policy Across Socio-Economic Areas. Public Health Nutrition, 2017, vol. 20, no. 18, pp. 3304-3315.

21. Yeomans M.G. Some Gimensions of a Planning Problem Residential-Agricultural Land Use Conflict in Metropolitan Rural-Urban Fringe Areas. Vancouver, 2002. 263 p.

\section{Information about the Author}

Nijabat O. Zarbaliyeva, Map Service Engineer, City Information Center, Bobruiskaya St., 7, 400074 Volgograd, Russian Federation, r-zarbalieva@mail.ru.

\section{Информация об авторе}

Ниджабат Омар кызы Зарбалиева, инженер картографической службы, Городской информационный центр, ул. Бобруйская, 7, 400074 г. Волгоград, Российская Федерация, r-zarbalieva@mail.ru. 